\title{
НОВЫЕ МЕТОДЫ НАПРАВЛЕННОГО ВОЗДЕЙСТВИЯ НА ТРИБОЛОГИЧЕСКИЕ СВОЙСТВА МАТЕРИАЛОВ В КОНТАКТЕ СО ЛЬДОМ И СНЕГОМ
}

\author{
Г. Ю. Гончарова, Ю.А. Кулагин, Ю. Г. Паршиков, Н. Д. Разомасов \\ ГАЛИНА ЮРЬЕВНА ГОНЧАРОВА - д.т.н., главный научный сотрудник МГТУ им. Н.Э. Баумана. \\ Всероссийский Научно-исследовательский институт холодильной промышленности - филиал ФБГНУ \\ «ФНЦ пищевых систем им. В.М. Горбатова»PAH. E-mail: galinagoncharova@mail.ru.
}

ЮРИЙ АЛЕКСАНДРОВИЧ КУЛАГИН - д.ф-м.н., ведущий научный сотрудник ФГУП «ЦНИИХМ». E-mail: kulaginyua@mail.ru.

ЮРИЙ ГРИГОРЬЕВИЧ ПАРШИКОВ - д.т.н., директор МЦАИ РАН. E-mail: parshikov62@rambler.ru.

НИКОЛАЙ ДМИТРИЕВИЧ РАЗОМАСОВ - научный сотрудник Всероссийского Научно-исследовательского института холодильной промышленности - филиала ФБГНУ «ФНЦ пищевых систем им. В.М. Горбаmова»PAH. E-mail: nrazomasov@yandex.ru.

105005, г. Москва, 2-я Бауманская ул., д. 5, стр. 1, Федеральное государственное бюджетное образовательное учреждение высшего образования «Московский государственный технический университет имени Н.Э. Баумана (национальный исследовательский университет)» (МГТУ им. Н.Э. Баумана).

115487, г. Москва, ул. Нагатинская, д. 16а, Федеральное государственное унитарное предприятие «Центральный научно-исследовательский институт химии и механики».

117997, г. Москва, ул. Профсоюзная, д. 65, стр. 6, Федеральное государственное бюджетное учреждение науки Межведомственный центр аналитических исследований в области физики, химии и биологии при Президиуме Российской академии наук (МЦАИ РАН).

127422, г. Москва, ул. Костякова, д. 12, Всероссийский Научно-исследовательский институт холодильной промышленности - филиал ФБГНУ «ФНЦ пищевых систем им. В.М. Горбатова» РАН.

Представлен обзор современных методов направленного воздействия на силу фрикиионного взаимодействия твёрдых тел с поверхностью льда и снега. Предложен метод модификаиии ледовых структур, основанный на внесении в воду для формирования ледового покрытия высокомолекулярных соединений, состав и концентрации которых связаны с формой, обработкой поверхности скольжения, удельной нагрузкой и скоростями движения твёрдых тел. Представлено описание оригинальной экспериментальной установки с вращающимся ледовым покрытием, позволяющей достигать высоких скоростей взаимодействия фрикиионной пары без повторения пройденной траектории.

Представлены результаты лабораторных и натурных экспериментов, подтверждающие возможность, как снижения, так и увеличения силь сопротивления скольжению, и приведено научное обоснование требования соразмерности характерного размера шероховатости скользящей поверхности полозьев с толщиной жидкостной пленки и квазижидкого слоя. Определены наиболее рациональные области использования предлагаемых методов, основные из которых - спорт высших достижений и решение широкого спектра инженерно-технических задач при освоении арктического региона России.

Ключевые слова: ледовые структуры, фрикционное взаимодействия, сила сопротивления скольжению, модифицирующие соединения. 


\title{
NEW METHODS OF DIRECTED INFLUENCE ON THE TRIBOLOGICAL PROPERTIES OF MATERIALS IN CONTACT WITH ICE AND SNOW
}

\author{
G. Yu. Goncharova ${ }^{1}$, Yu.A. Kulagin ${ }^{2}$, Yu. G. Parshikov ${ }^{3}$, N. D. Razomasov ${ }^{4}$ \\ ${ }^{15}$ ul. Baumanskaya 2-ya, Moscow, 105005, Russia. Bauman University. \\ ${ }^{2} 6 a$, Nagatinskaya, Moscow, 115487, Russia. Central research Institute of chemistry and mechanics. \\ ${ }^{3} 65$ Profsoyuznaya Str., Moscow, 117342, Russia; Interdepartmental Center for Analytical Research in Physics, \\ Chemistry, and Biology, Presidium RAS.
}

${ }^{4} 12$ Kostyakova Str., Moscow, 127422, Russia. All-Russian Scientific Research Institute of Refrigeration Industrybranch of V.M. Gorbatov Federal Research Center for Food Systems of Russian Academy of Science

The report provides an overview of modern methods of directed influence on the force of frictional interaction of solids with the surface of ice and snow. A method for modifying ice structures is proposed, based on the introduction of high-molecular compounds into the water to create the ice cover, the composition and concentration of which are related to the shape, treatment of the sliding surface, specific load and speeds of movement of solids. The paper describes an original experimental installation with a rotating ice cover, which allows achieving high interaction speeds of a friction pair without repeating the past trajectory.

The results of laboratory and field experiments, confirming the opportunity for both gains and strength increases slip-resistance, and provides a scientific basis for the requirement of proportionality characteristic size of roughness of a sliding surface of the runners with the thickness of the liquid film and the quasi-liquid layer. The most rational areas of use of the proposed methods are identified, the main of which are sports of the highest achievements and solving a wide range of engineering and technical problems in the development of the Arctic region of Russia.

Key words: ice structures, frictional interaction, slip resistance force, modifying compounds.

\section{Введение}

В современном мире лёд продолжает оставаться в центре внимания учёных и практиков. Лёд - основа большинства зимних видов спорта и искусственное улучшение его скользящих свойств одна из основных проблем спортивной индустрии ведущих мировых держав. Учитывая его доступность, по-прежнему остаются актуальными задачи направленного изменения - модификации - его естественных свойств применительно к широкому кругу инженерных задач. Зачастую задачи эти диаметрально противоположны: либо, увеличение прочностных свойств для использования льда в качестве строительного материала в арктической зоне, либо необходима разработка методов его эффективного разрушения для прохода судов в полярных акваториях. Общее всех этих задач - поиск эффективных методов направленного изменения природных свойств льда.
Задача этой статьи - привлечь внимание специалистов к неизвестным ранее возможностям направленного регулирования свойств естественного льда и представить наиболее рациональные способы использования модифицированного льда.

\section{История вопроса}

Наиболее богатую историю имеют исследования, посвящённые скольжению твёрдых тел по льду. Коэффициент трения скольжения по льду $\mu_{\mathrm{k}}$ чрезвычайно мал и составляет от одной десятой до одной сотой доли этого показателя у металлов. Он также меньше, чем у смазанных маслом металлических поверхностей $\left(\mu_{\mathrm{k}}=0,1\right)$, и того же уровня или меньше, чем у известного своим низким коэффициентом трения скольжения фторопласта $\left(\mu_{\mathrm{k}}=\right.$ $0,05)$ и являющегося твердым смазочным материа- 
лом дисульфида молибдена $\mathrm{MbS}_{2}\left(\mu_{\mathrm{k}}=0,05\right)$. Решением этой проблемы занимались различные научные школы, создавались научные теории. В начале прошлого столетия Рейнольдс «распахнул дверь» в мир исследований трения льда, объяснив низкие значения сопротивления скольжению коньков появлением плёнки воды, образующейся в результате давления конька на поверхность льда. Эта теория получила название «Теории таяния от давления» [1]. Однако, эта теория не даёт объяснения появлению жидкостной плёнки под лезвием конька, т.к. увеличение давления на 0,1 МПа понижается точку плавления льда всего на $0,0075{ }^{\circ} \mathrm{C}$. Поэтому для появления водяной плёнки под лезвием конькобежца (массой 70 кг) необходимо создать удельную нагрузку, равную 80 - 105 МПа, т.е. более чем в 60 раз превышающую нагрузку, создаваемую весом спортсмена. При этом предел прочности льда на сжатие ( 2-2,5 Мпа) на порядки ниже, чем требуемая нагрузка.

В дальнейшем Боуден и коллеги предположили, что причиной появления талой воды на поверхности льда, оказывающей смазочный эффект, является не давление, а действие джоулевой теплоты, выделяющейся в процессе трения скользящего тела. Некоторое время считалось, что подобная «Теория таяния от трения» исчерпывающе объясняет механизм низкого трения льда. В работе Боудена и Хьюза [2] была сделана попытка оценить возможность плавления льда под действием теплоты трения с учётом сопровождающих данный процесс тепловых явлений. Однако впоследствии было доказано, что во всём реальном диапазоне определяющих скольжение макропараметров невозможен режим жидкостного трения по всей длине лезвия конька без подвода извне теплоты или непосредственно смазывающей жидкости.

Сомнения в состоятельности «Теории таяния от трения» привели Макконика к созданию «Тео-

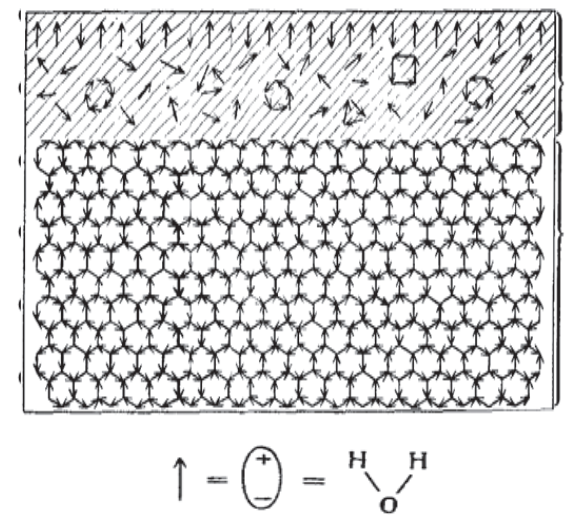

Квазижидкий слой

Внутренняя область кристалла льда

Рис. 1а. Модель строения квазижидкого слоя рии смазки водяными парами» (Lubrication of vapor film). Он полагал, что лыжа из магнезии хорошо скользит в силу адгезии к поверхности трения водяных паров, которые играют роль смазки. Основой теории послужила аналогия с графитом: коэффициент трения графита, высушенного в вакууме, велик, но при адгезии водяных паров значительно снижается.

В настоящее время основное развитие получила «Теория квазижидкого слоя», согласно которой вблизи точки плавления на поверхности льда существует тонкая плёнка, проявляющая свойства льда и воды одновременно, получившая название переходного или квазижидкого слоя. Первым мысль о существовании на поверхности льда квазижидкого слоя высказал английский физик Фарадей (1850 г.). Спустя более чем 100 лет, в 1951 году, американский химик Уайл, воспользовавшись аналогией с двойным электрическим слоем, образующимся на поверхности ионных кристаллов, теоретически обосновал возможность существования на поверхности льда «квазижидкого» слоя. Количественную же теорию построил Флетчер [3] и вычислил толщину переходного слоя на свободной поверхности льда, как функцию температуры. В схематичном виде результаты, вытекающие из теории Флетчера, представлены на рис. 1a.

Убедительное экспериментальное подтверждение теория Флетчера получила только к концу двадцатого столетия. Группа учёных Берклеевской лаборатории под руководством Гейбора Соморжая применила ко льду методику исследования поверхностей материалов магнитных носителей [4] и обнаружила, что при температурах, близких к плавлению льда, на его поверхности отсутствует практически каждая вторая молекула. «Недостающие» молекулы воды настолько интенсивно вибрировали, что приборы не могли их обнаружить. Они перемещались только в направлении

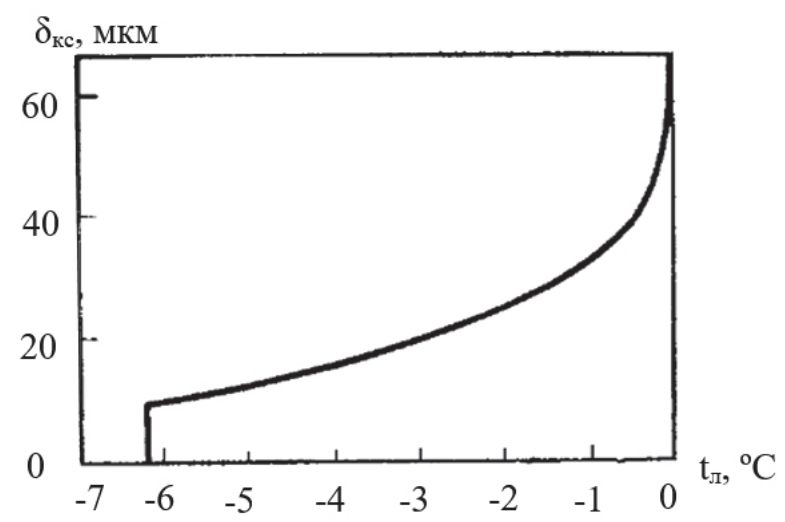

Рис. 1б. Толщина «квазижидкого» слоя по модели Флетчера 
вверх-вниз, а перемещений в горизонтальной плоскости, как в истинной жидкости, не происходило. В более поздних работах Г. Соморжая и Мишеля Ван Хова (1996 - 1997 гг.) были представлены данные о наличии «квазижидкой» плёнки на поверхности льда вплоть до температуры минус $183{ }^{\circ} \mathrm{C}$ (90 K). При этом толщина её со снижением температуры постепенно уменьшается до величины одномолекулярного слоя. Влияние температуры льда на толщину «квазижидкого» слоя на его поверхности отражает рис. 1б. Таким образом, практически все теории объясняют низкий коэффициент трения льда наличием жидкостной плёнки между твёрдым телом и льдом, однако механизм её возникновения трактуется по-разному.

К концу XX века тотальная коммерциализация большого спорта привела к ситуации, когда постоянное обновление скоростных мировых рекордов потребовало привлечения самых современных научно-технических разработок, и в области модификации свойств льда, в том числе. Теоретически и экспериментально доказано, что в начальной фазе скольжения всегда присутствует зона «сухого» и смешанного трения, а наиболее предпочтительный жидкостной режим трения возможен только при искусственном введении дополнительной смазки в зону контакта. Все попытки подойти к этой проблеме «сверху», со стороны конька, потерпели неудачу; даже традиционные лидеры в конькобежном спорте, голландцы, инженерно не справились с этой задачей и не смогли добиться равномерности распределения смазывающей жидкости по длине лезвия. Далее, по всей видимости, «сдетонировал» весь накопленный прежде опыт, и появилась идея принципиального иного подхода к снижению трения скольжения - создания модифицированного ледового покрытия, потенциально содержашего необходимую смазку, равномерно распределённую в межкристаллическом пространстве, и выделяюшуюся при движении конька, полоза бобов или саней.

\section{Метод модифицирования физико-механических свойств льда}

На рубеже двадцать первого столетия авторами был предложен и успешно апробирован метод направленного воздействия на свойства льда $[5,6]$, основанный на внесении в воду микро доз структурирующих добавок - высокомолекулярных химических соединений, которые способствуют образованию регулярной кристаллической структуры и в процессе кристаллизации, не замерзая, дислоцируются преимущественно в межкристаллическом пространстве и на поверхности льда. При скольжении конька они являются потенциальным источником дополнительной смазки и существенно снижают силу сопротивления скольжению. Начиная с 2000-х годов, были проведены теоретические и экспериментальные исследования [7, 8], позволившие сформировать критерии отбора модифицирующих соединений, позволившие системно подойти к модификации льда и отойти от малопродуктивного перебора полимеров, производимого из общих и интуитивных соображений. В результате были определены группы соединений, в наибольшей степени способствующих снижению фрикционного взаимодействия конька со льдом, а также рекомендуемые диапазоны концентрации вносимых ингредиентов, не приводящие к потере твёрдости ледовой поверхности.

В соответствии с молекулярно-механической концепцией трения оно имеет двойственную природу: силу трения можно представить, как сумму молекулярной $\mathrm{F}_{\text {мол }}$ (адгезионной) и механической $\mathrm{F}_{\text {деф }}$ (деформационной) составляющих. Внесение при заливке льда полимерных соединений с температурой кристаллизации (или стеклования) минус 30 - минус $70{ }^{\circ} \mathrm{C}$ и минимальными значениями поверхностного натяжения уменьшает силу сопротивления скольжению, воздействуя на адгезионную составляющую трения. Для модификации льда равнинных катков и неплоскостных спортивных сооружений (санно-бобслейных трасс) были выбраны кремнийорганические масла и фторкремнийорганические микроэмульсии, имеющие минимальное поверхностное натяжение из всех известных к настоящему времени соединений. Поверхностное натяжение данных групп веществ ниже, чем у воды в 3-3,5 раза, что обеспечивает максимально возможное снижение работы адгезии в зоне контакта. При взаимодействии конька или полоза спортивного снаряда со льдом полимеры способствуют образованию жидкостной плёнки в зоне контакта и реализации гранично-гидродинамического режима трения.

Лабораторные исследования и натурные эксперименты с ведущими спортсменами подтвердили эффективность разработанных методов снижения адгезионной составляющей силы сопротивления скольжению и позволили оптимизировать, как саму технологию введения модификаторов, так и состав, и концентрации вводимых компонентов. Однако в ходе проведения экспериментов для полозьев с разной обработкой поверхности скольжения достигалось минимальное значение силы трения, обусловленное предельным снижением адгезионной составляющей. Это позволило предположить, что дальнейшее снижение силы фрикционного взаимодействия пары «полоз - лед» 
возможно только за счет снижения деформационной составляющей, определяемой качеством классом (чистотой) обработки поверхности скольжения. Таким образом, следующей задачей исследования было определение геометрических характеристик поверхности скольжения для достижения соразмерности предельной величины микронеровностей с толщиной, образуемой при скольжении жидкостной плёнки.

Если же высота микронеровностей скользящей поверхности полоза ( $\mathrm{Ra})$ при контакте с ледовой поверхностью существенно превышает оценочное значение толщины жидкостной плёнки (h), то деформационная составляющая силы трения значительно превышает адгезионную и нивелирует преимущества, от модификации ледовой структуры. Учесть и математически формализовать все физические механизмы возникновения пленки жидкости в зоне контакта не представляется возможным, поэтому поставленная задача решалась путём проведения комплексных экспериментальных исследований.

\section{Исследование микропараметров скользящих поверхностей спортивных снарядов с помощью оптической микроскопии}

В ведущих спортивных державах спортивные снаряды к выступлениям членов сборных готовят специализированные сервисные службы, используя, по их мнению, наиболее современные и перспективные методики обработки поверхностей скольжения. Для оценки качества обработки поверхностей скольжения спортивных снарядов, используемых ведущими спортсменами России,

\section{3-Dimensional Interactive Display}

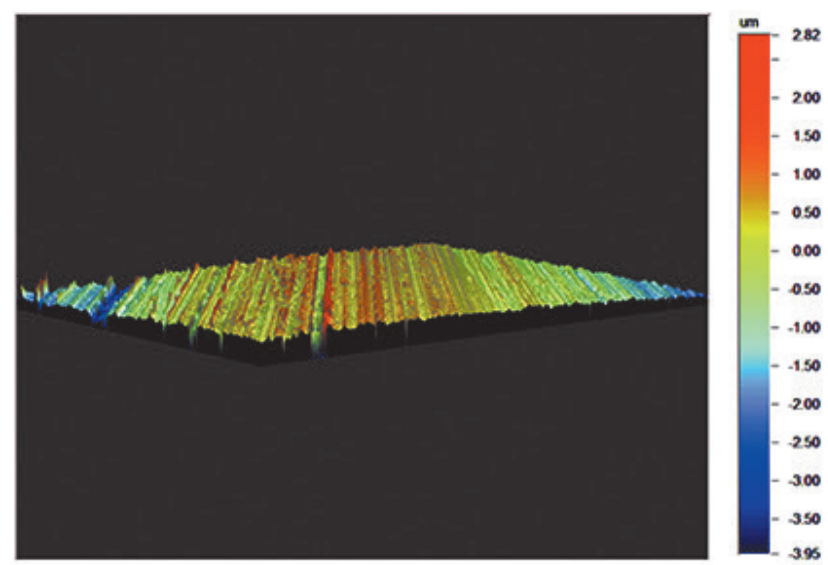

Рис. 2а. Изображение участка полоза, обработанного сервисменами было проведено исследование нескольких участков полозьев боба одного из лидеров сборной России по бобслею. Исследование проводилось методом оптической микроскопии. Изображение участка лезвия, обработанного сервисменами самостоятельно, приведено на рис. 2 a.

Рассматриваемый участок представлял собой прямоугольник с размерами сторон 303×230 мкм. Посередине каждой из сторон проведены взаимно перпендикулярные линии измерения шероховатости скользящей поверхности на профилометре Sensofar Sneox. Расположение линий, через которые проходят плоскости, в которых проводилось исследование рельефа, показано на рис. 26.

На рисунках 3а и б представлены проекции рельефа участка скользящей поверхности на плоскость, проходящую через ось Х и Ү.

Можно видеть, что максимальная высота микровыступов на поверхности скольжения достигает 2,2 мкм по оси X и 1,74 мкм по оси Y, что значительно превышает толщину пленки жидкости, по которой происходит скольжение спортивного снаряда. Такой низкий уровень чистоты поверхности может нивелировать преимущества, получаемые при скольжении по пленке жидкости даже при использовании модифицирующих соединений, не говоря уже о ледовом покрытии, залитом чистой водой. В связи с этим был предложен иной способ обработки поверхности полозьев, включающий несколько этапов:

1) Ручная полировка поверхности скольжения до уровня $\mathrm{R}_{\mathrm{z}}=1,2-1,4$ мкм;

2) Дополнительная обработка скользящей поверхности полоза методом лазерной абляции с нанесением структуры двойной шероховатости различной геометрии;

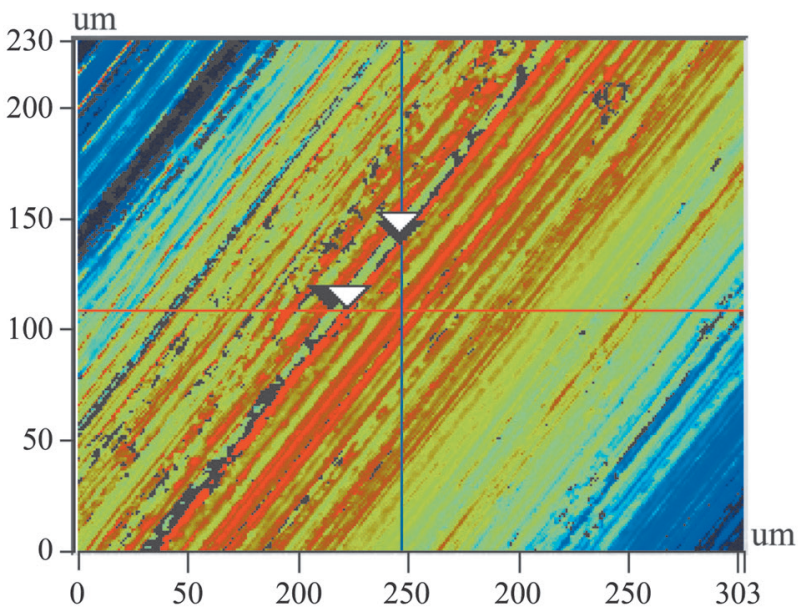

Рис. 2б. Расположение плоскостей исследования рельефа: красная линия - ось X, синяя линяя - ось Y 


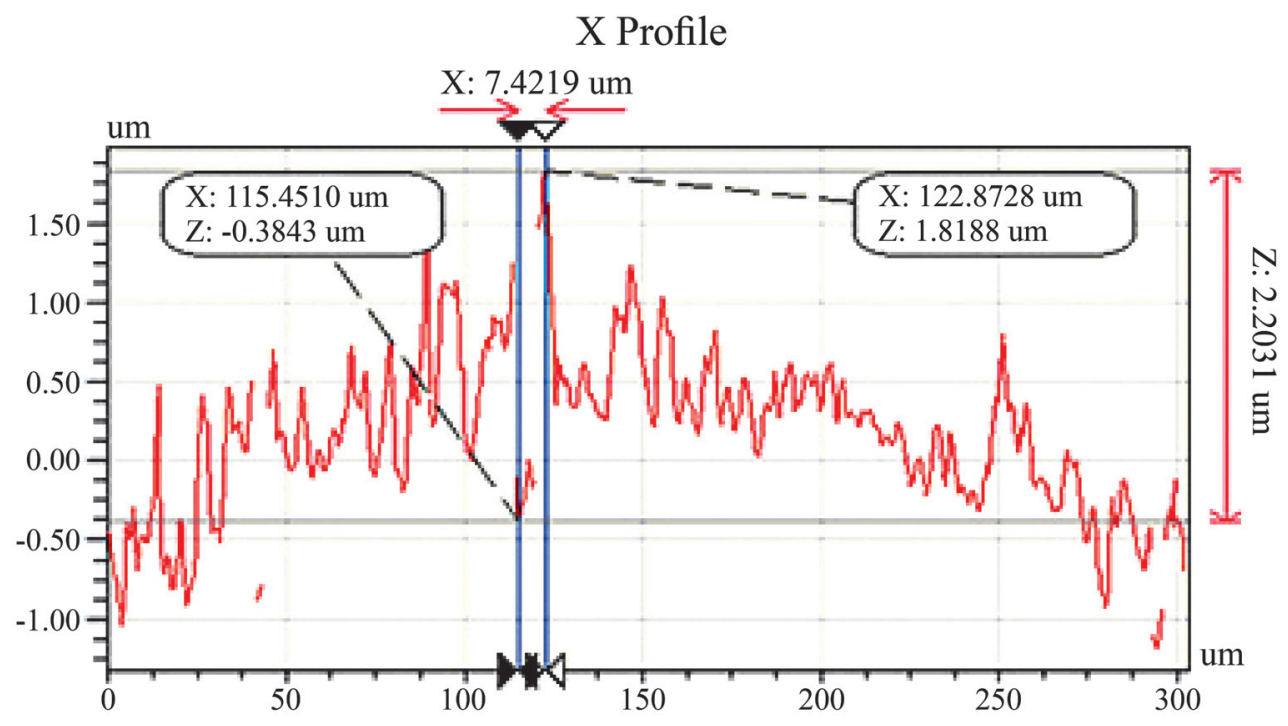

Рис. 3а. Проекция рельефа на плоскость, проходящую через ось X

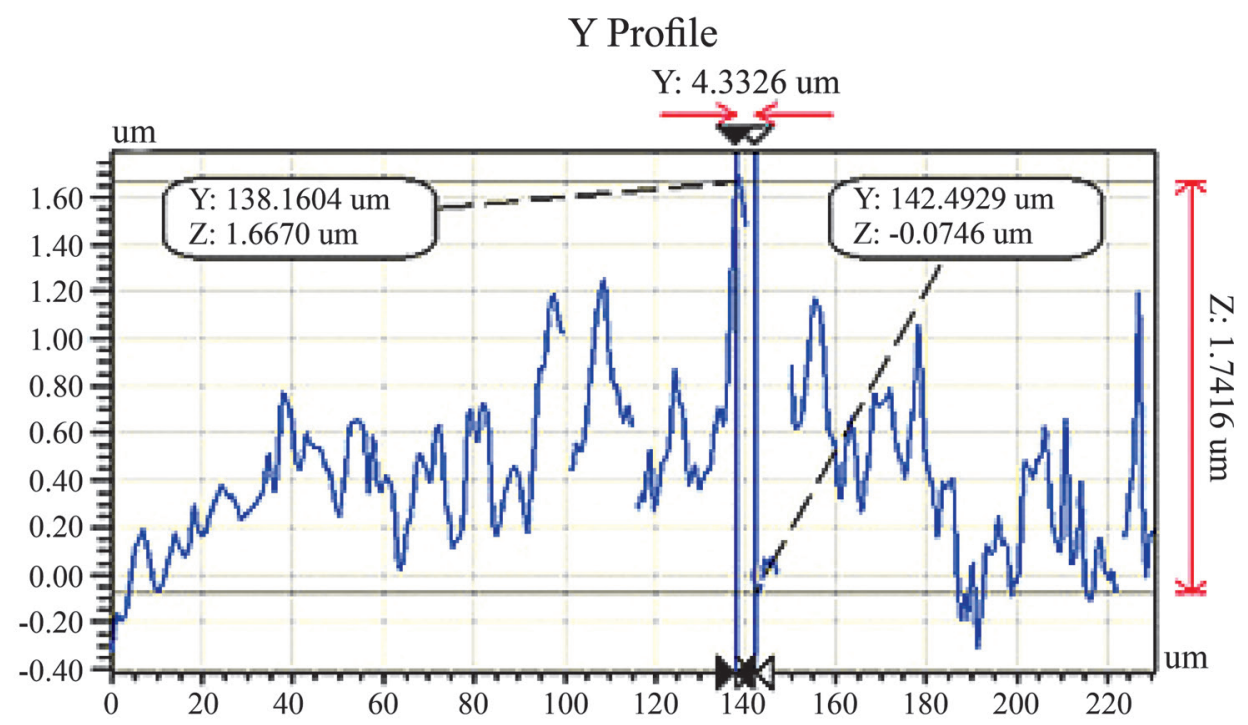

Рис. 3б. Проекция рельефа на плоскость, проходящую через ось Y

Данный способ позволяет значительно улучшить качество обработки скользящей поверхности спортивных снарядов. Так, на рис. 4а приведено изображение участка полоза, обработанного по данной методологии, а на рис. 46 - расположение плоскостей исследования рельефа.

На рис. 5а представлена проекция рельефа участка скользящей поверхности на плоскость, проходящую через ось $\mathrm{X}$, а на рис. 56 - через ось Y.

Из приведенных изображений видно, что максимальная высота микровыступов после проведения обработки, согласно предлагаемому способу, уменьшилась более чем на порядок и составила
0,12-0,19 мкм по осям X и Y. Это значение по порядку величины может быть сопоставимо с толщиной плёнки жидкости, возникающей в зоне контакта. Однако, достоверных аналитических методов расчёта толщины возникающей в зоне контакта жидкостной плёнки до настоящего времени не предложено, поэтому влияние обоих факторов (модификации льда и лазерной обработки поверхности скольжения) определялось экспериментальным путём.

Завершающим этапом дополнительной обработки было нанесение методом лазерной абляции структуры, существенно увеличивающей гидро- 
3-Dimensional Interactive Display

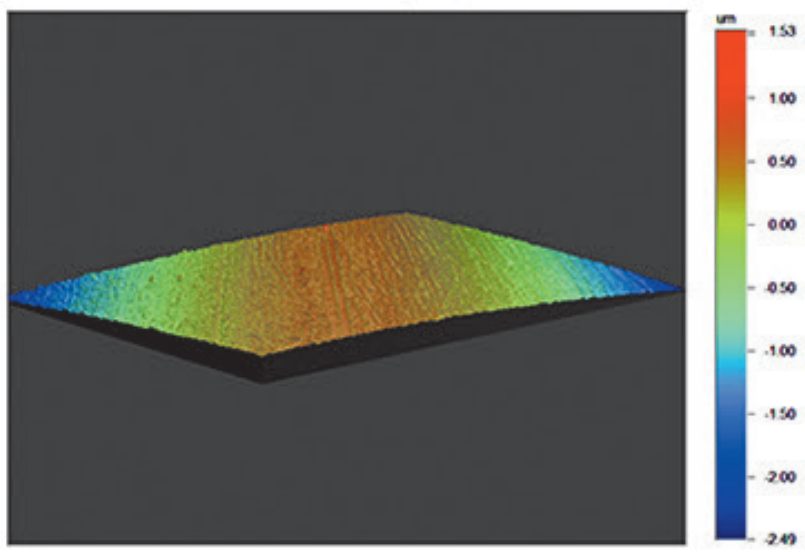

Рис. 4а. Изображение участка полоза с лазерной обработкой

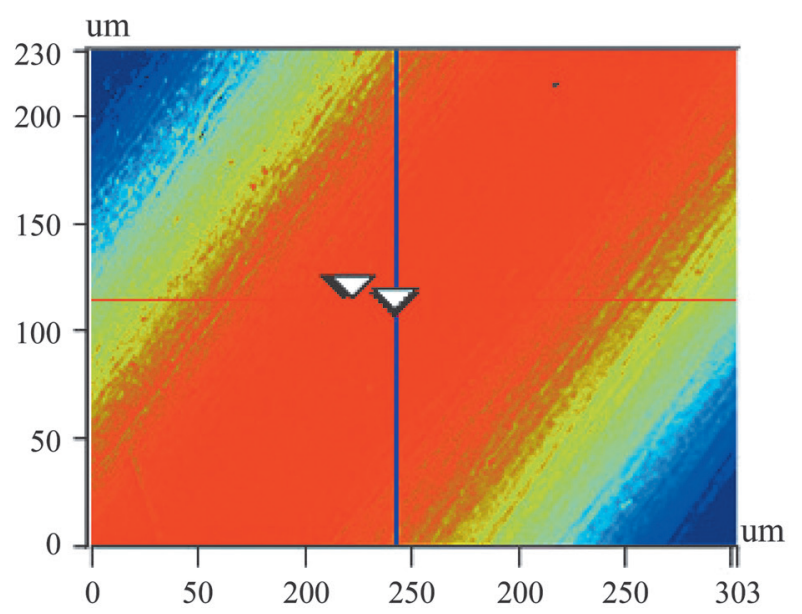

Рис. 4б. Расположение плоскостей исследования рельефа

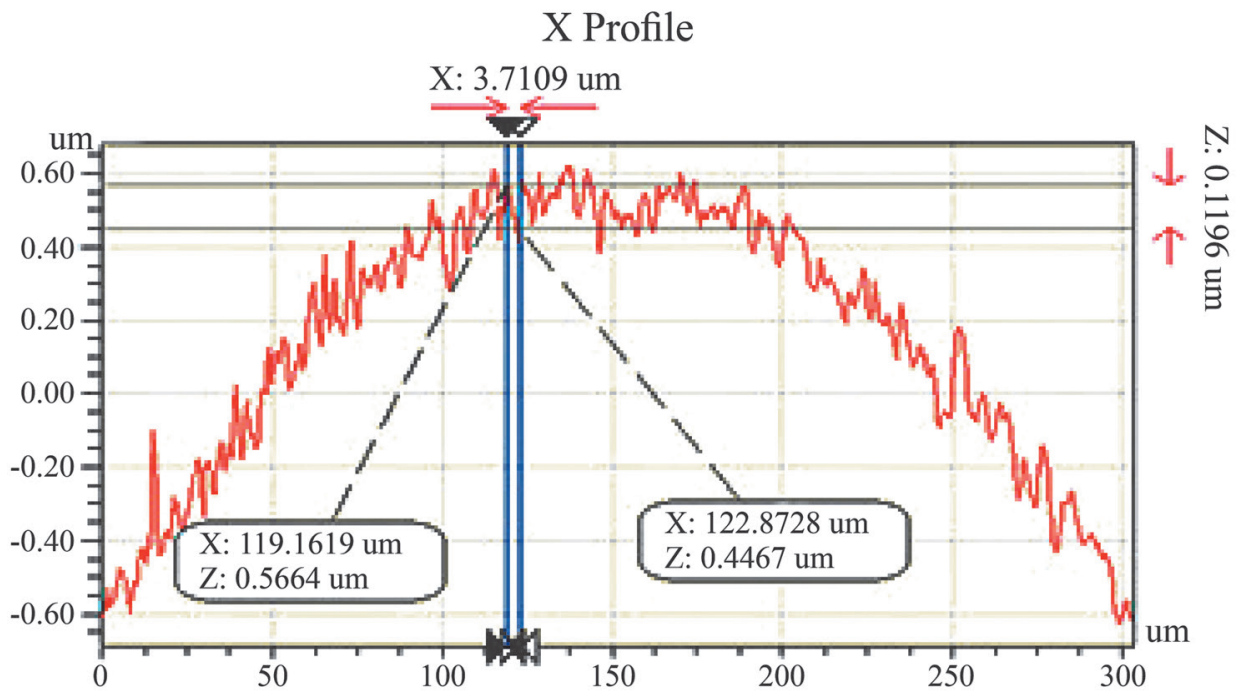

Рис. 5а. Проекция рельефа участка скользящей поверхности на плоскость, проходящую через ось $\mathrm{X}$

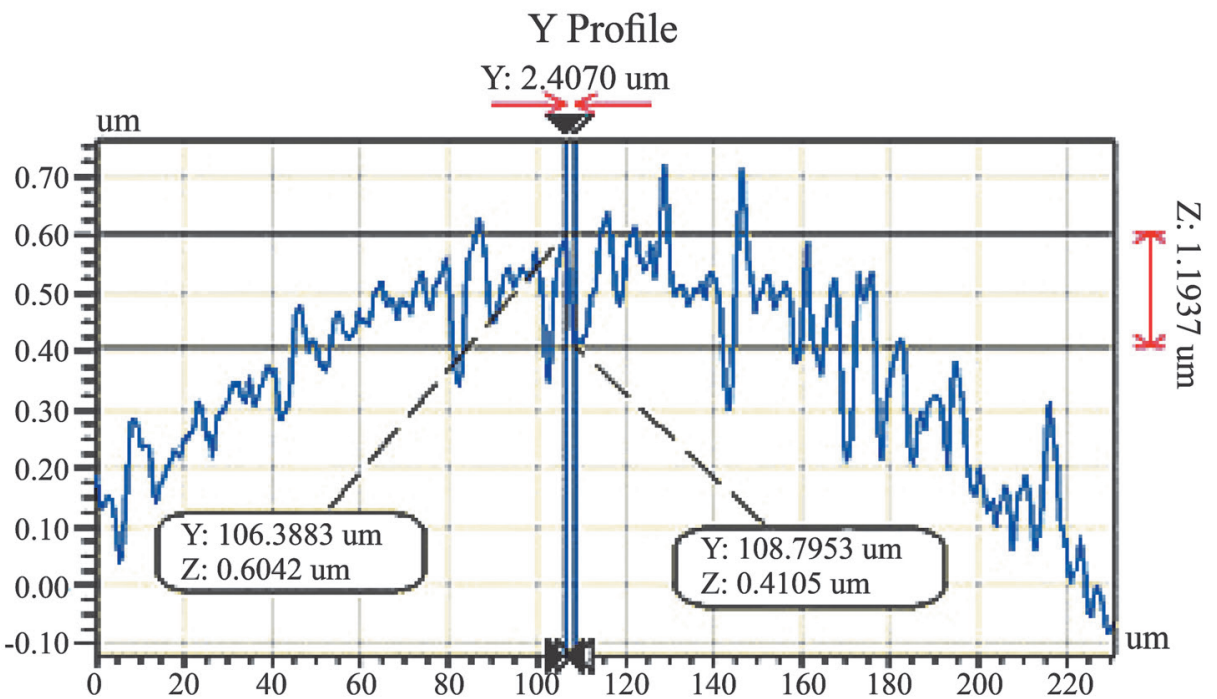

Рис. 5б. Проекция рельефа участка скользящей поверхности на плоскость, проходящую через ось Y 


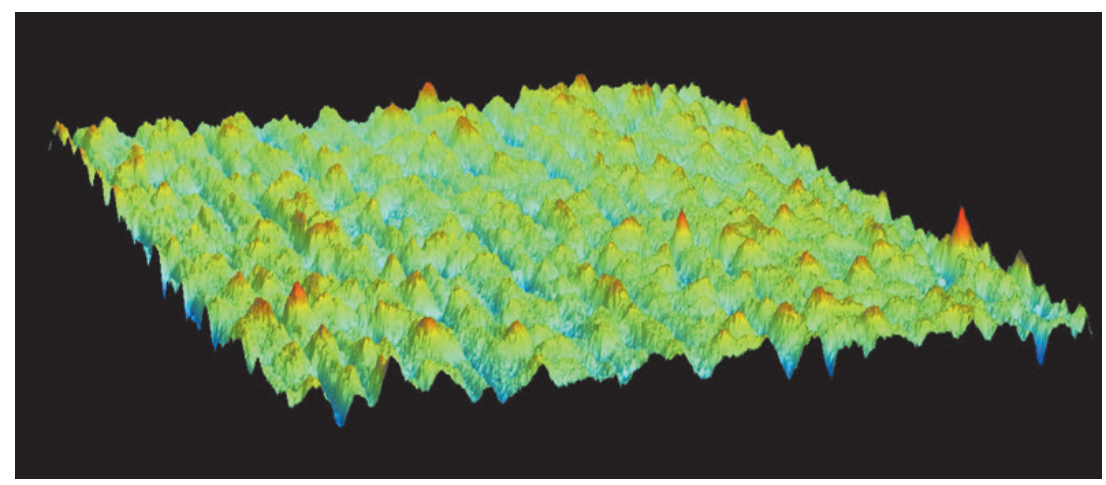

Рис. 6. Структура двойной шероховатости $\left(R_{a}=40-60\right.$ нм

фобность скользящей поверхности. Наиболее рациональным подходом, разделяемым многими научными школами, стало воспроизведение структуры природных материалов, обладающих уникальными сверхгидрофобными свойствами: листья лотоса, перья птиц, кутикулы крыльев цикад [9-15].

Угол их смачивания достигает $162^{\circ}$ (для сравнения угол смачивания самого гидрофобного из известных материалов - фторопласта - не превышает $112^{\circ}$ ). Впервые «эффект лотоса» был обнаружен и описан в конце XX-го века Бартлоттом и Найнуйсом. Он обусловлен присутствии на поверхности структуры «двойной шероховатости» - шероховатости микромасштаба, покрытой структурой шероховатости наноразмера (в некоторых работах её называют «нановорсистостью»). Внешний вид структуры, искусственно нанесённой на отполированную поверхность полоза или конька, показан на рис. 6.

Исследованию фрикционного взаимодействия твёрдых тел со льдом посвящено достаточно большое число работ. Однако большинство из них не применимо к скольжению бобов и саней в силу узкого диапазона изменения и низких (порядка сантиметров в секунду) значений скоростей в проведённых экспериментах. Если же скорости были соизмеримыми со скоростями движения спортивных снарядов, то процесс скольжения осуществлялся по многократно повторяющейся траектории, что приводило к аккумуляции тепла трения на этих участках и искажению реальной зависимости фрикционного взаимодействия от скоростных характеристик. Для изучения трения в условиях высоких скоростей и однократного прохождения полозом поверхности льда потребовало создания установки, сочетающей высокие скорости и отсутствие повторяемости траектории. Было предложено оригинальное конструктивное решение и изготовлен экспериментальный стенд, позволяющий плавно изменять скорость взаимодействия фрик- ционной пары и осуществлять перемещение испытываемого полоза на льду по спирали без повторения пройденной траектории (винтовой линии).

Схема и внешний вид экспериментального стенда с вращающимся ледовым покрытием изображены на рисунках 7а и б. Скользящее полотно (СП) спортивного снаряда представлено красным цветом, для экспериментального определения силы сопротивления скольжению лезвия конька или полоза по льду использовались электронные динамометры. Экспериментальный унифицированный стенд состоит из трёх основных частей: вращающегося барабана с намороженным ледовым покрытием - 1 (рис. 7б), подвижной платформы с закреплённым лезвием конька или полоза - 2 холодильной машины. Вращающийся барабан помещён в защитный короб для безопасности работы и возможности сбора воды при оттаивании ледового покрытия. Стенд укомплектован электрическим щитом управления с подключенными к нему всеми элементами для непрерывной фиксации результатов.

Крепление направляющих рельсов для подвижной платформы с площадкой для крепления динамометра устроено таким образом, что позволяет менять угол установки исследуемого лезвия к оси вращения ледового покрытия от 70 до $90^{\circ}$.

Ниже представлены результаты исследований, полученные для 5-ти лезвий: одного контрольного со штатной обработкой поверхности и 4-х лезвий с различными геометрическими соотношениями нанесённой наноструктуры на скользящую поверхность конька, с внесением модифицирующей смеси в состав льда, рекомендуемого для конькобежного спорта (рис. 8).

На основании проведенных экспериментальных исследований и их графической визуализации можно сделать следующие выводы:

- при идентичных условиях в исследуемом диапазоне скоростей лезвие 30 (21) обладает наи- 


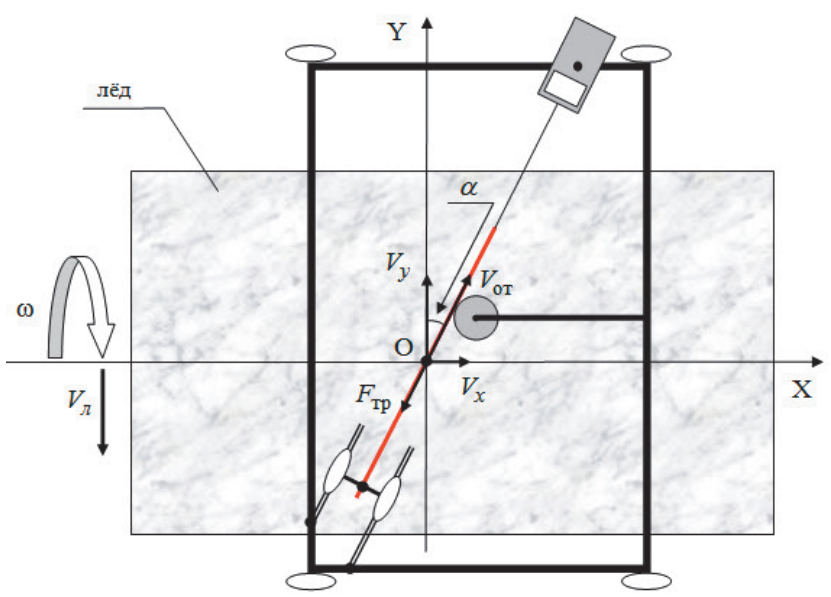

Рис. 7а. Схема испытательного стенда

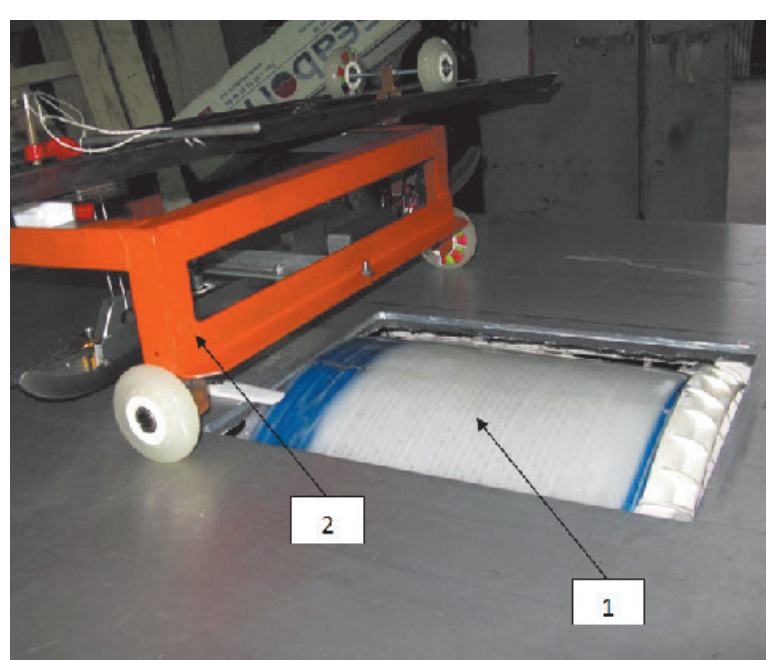

Рис. 7б. Вращающийся барабан с намороженным ледовым покрытием и подвижная платформа с закреплённым лезвием конька

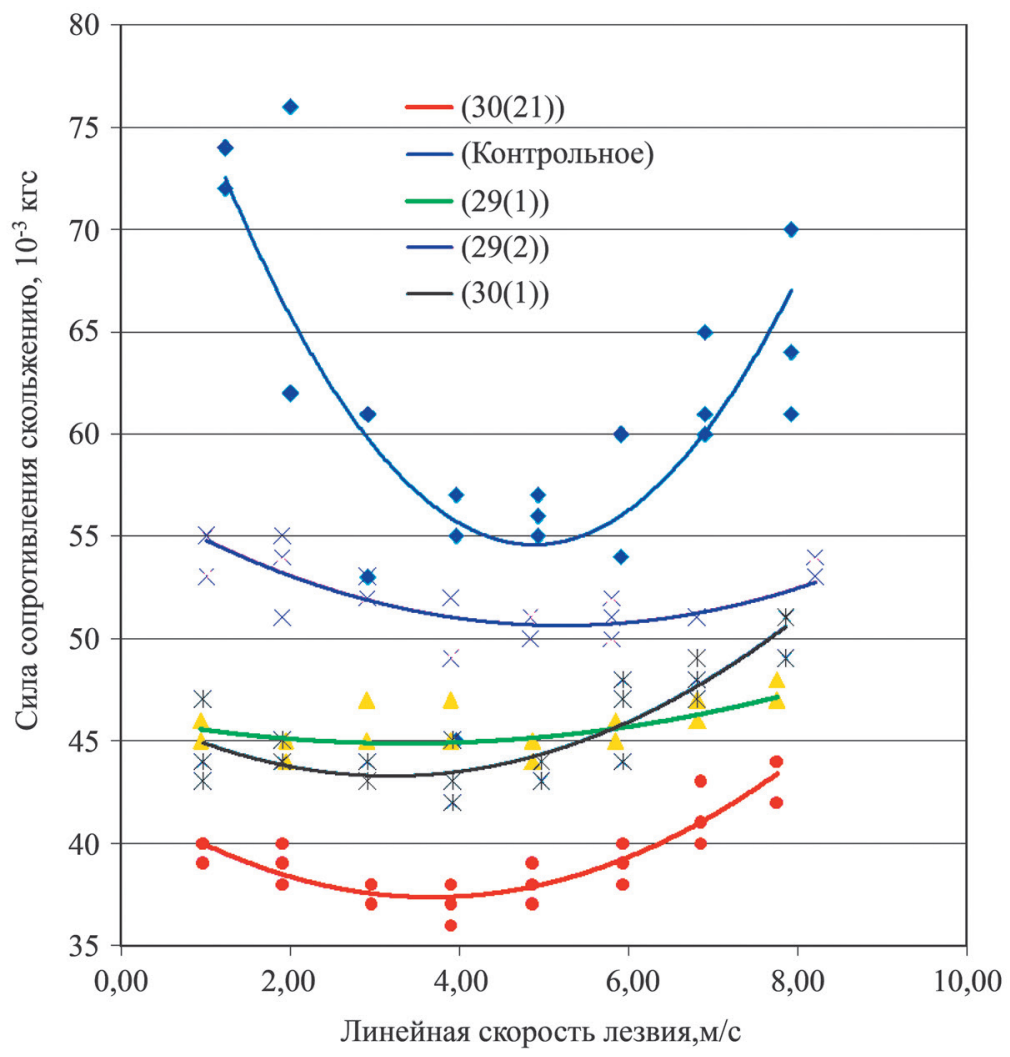

Рис. 8. Результаты исследований лезвий с различной наноструктурой на модифицированном льду

лучшими фрикционными свойствами. Сила сопротивления скольжению по льду лезвий 30 (21) по сравнению с контрольными лезвиями меньше в среднем на $30-50 \%$;

- зависимость триботехнических характеристик фрикционной пары «конёк-лёд» от скорости скольжения имеет выраженный экстремальный характер, и минимум силы сопротивления наблюдается при скоростях $3 \div 6 \mathrm{~m} / \mathrm{c}$, после чего она начинает возрастать;

- наиболее выраженный параболический характер зависимости триботехнических характери- 
стик от скорости скольжения наблюдается у контрольного лезвия - разброс значений силы сопротивления скольжению составляет 27-37 \%;

- разброс значений силы сопротивления скольжению лезвия 30(21) по льду составляет 16-22 \%. Минимальное значение силы сопротивления достигается при скорости $2 \div 4 \mathrm{M} / \mathrm{c}$.

Результаты испытаний, полученные на ледовых покрытиях, модифицированных различными группами присадок, показали, что сопротивление скольжению во всех реальных скоростных диапазонах может быть снижено до $24 \%$ на контрольном лезвии и дополнительно от 20 до 29 \% для лезвий с лазерной обработкой. Данный результат свидетельствует о том, что оба фактора - модификация льда и поверхности скольжения- существенно влияют на силу сопротивления трению и суммирование этих характеристик может значительно улучшать результативность спортсменов в скоростных видах спорта.

Экспериментальные исследования скоростных свойств на плоскостных ледовых объектах проводились с использованием специализированного оборудования и скользиметров, имитирующих скольжение спортсмена с пневмо или механическим приводом и системой хронометража. Было показано, что внесение смесей модифицирующих соединений в рекомендуемом диапазоне концентраций позволяет существенно (до 50 \%) снижать силу сопротивления скольжению скользиметра. Эти результаты успешно используются в России при проведении соревнований по ледовым видам спорта самого высокого уровня. Однако сфера применения методов направленного воздействия на природные свойства льда не ограничивается индустрией спорта. Активное освоение Арктики требует решения большого числа задач, связанных с использованием неограниченных запасов снега и льда в северных регионах в качестве полноценного строительного материала для различных народно-хозяйственных и военнопромышленных объектов. Искусственное увеличение (или снижение) силы трения важно при созда- нии взлётно-посадочных полос, транспортных путей, переправ, площадок для размещения и укрытия объектов инфраструктуры и т.д. Внесение модификаторов приводит также и к значительному снижению хрупкости льда. Поэтому использование модификации ледовых покрытий, особенно в сочетании с упрочнением льда армирующими элементами открывает большие перспективы в плане кардинального снижения количества завозимых авиацией строительных и конструкционных материалов.

Исследование выполнено при финансовой поддержке РФФИ в рамках научного проекта № 20 08-00120.

\section{Лuтература}

1. Маэно Н. Наука о льде. - М.: Мир. Москва. 1988.

2. Bowden F.P., Hughes T.P. The Proc. Roy. Soc. London. 1939. V. A 172. P. 280-298.

3. Fletcher N.H. Philosophical Mag. (London). 1968. V. 18. P. 287-300.

4. http://www.lbl.gov/Publications/Currents/Archive/Sep1996-Currents. html (дата обращения: 5.10.2009)

5. Гончарова Г.Ю., Нефёдкин С.И. Холодильная техника. 2005. №6. С. 6-8.

6. Гончарова Г.Ю. Холодильная техника. 2007. №7. C. $12-16$.

7. Гончарова Г.Ю. Холодильная техника. 2009. №9. C. 44-51.

8. Бузник В.M. Холодильная техника. 2019. № 11 . C. $40-45$.

9. Groenendjik M.N.W. Laser Technol. 2008. V. 3. P. 44.

10. Goncalves G., Marques P.A.A.P., Trinadade T., Neto C.P., Gandini A. J. Colloid Interface Sci. 2008. V. 324. P. 42.

11. Balu B., Breedveld V., Hess D.W. Langmuir. 2008. V. 24. P. 4785.

12. Barthlott $W$., Neinhuis C. Planta. 1997. V. 202. P. 1.

13. Neinhuis C., Barthlott W. Ann. Botany. 1997. V. 79. P. 667.

14. Onda T., Shibuichi S., Satoh N., Tsujii K. Langmuir. 1996. V. 12. P. 2125.

15. Shibuichi S., Onda T., Satoh N., Tsujii K. J. Phys. Chem. 1996. V. 100. P. 19512. 